\title{
Desempenho fiscal do estado do Rio Grande do Sul: uma análise do período pós Lei de Responsabilidade Fiscal - 2004 a 2012
}

Nelton Carlos Conte"

\section{Resumo}

O peso da dívida pública para as finanças públicas no estado do Rio Grande do Sul tem, nas últimas três décadas, centrado debates políticos, orçamentários e financeiros, sendo a culpa atribuída aos baixos níveis de investimento e dos constantes déficits primários. Neste cenário, a Lei de Responsabilidade Fiscal (LRF) (Lei Complementar n. 101/2000), ao consolidar regras quantitativas e de procedimentos que visavam reduzir o grau de discricionariedade nas políticas orçamentária e fiscal, definiu um arcabouço mais robusto e abrangente para a política fiscal a ser seguido por todos os níveis de governo. Assim, este artigo busca avaliar se a LRF contribui para melhoria dos indicadores fiscais do estado do Rio Grande do Sul, tendo por período de análise os anos de 2004 a 2012. Por meio de uma pesquisa descritiva, quantitativa, baseada em um estudo de caso, verificou-se que, apesar da importância de normas como a LRF, essa não foi suficiente para, por si só, garantir a melhoria da situação fiscal do estado do RS, onde o gasto público e o endividamento apresentaram crescimento superior ao da Receita Corrente Líquida (RCL).

Palavras-chave: Dívida pública. Lei de responsabilidade fiscal. Finanças pública. Estado do Rio Grande do Sul.

Bacharel em Ciências Contábeis. Especialista em Contabilidade Gerencial e Finanças. Mestre e Doutorando em Desenvolvimento Regional (Unisc). Professor da Faculdade de Ciências Econômicas, Administrativas e Contábeis (Feac) da Universidade de Passo Fundo (UPF). E-mail: conte@upf.br 


\section{Introdução}

A questão fiscal esteve no centro da evolução da economia brasileira e foi um dos principais determinantes de seu desempenho ao longo dos últimos trinta anos. Como destaca Levy (2010) o desequilíbrio fiscal que se acumulou do final dos anos 1970 em diante foi provavelmente uma causa importante para o longo período de inflação e estagnação do crescimento que se estendeu até o início dos anos 1990.

Nas décadas de 1980 e 1990 vigorava na economia brasileira, de acordo com Marques Junior (2012), o regime de restrição orçamentária fraca em que a condução da política fiscal, por esfera de governo, implicava déficits públicos e dívida pública crescente. Isto é, não havia maior preocupação com o descontrole fiscal, pois os três níveis de governo contavam com o financiamento via receita de senhoriagem e o imposto inflacionário.

Diante desse cenário, o Plano Real, arquitetado no ano de 1994, buscou dar um encaminhamento, embora parcial, dos problemas fiscais, tanto em termos de desempenho, quanto em termos institucionais. Seu principal mérito foi o de criar estratégias de estabilização da inflação.

Como assinalam Gremaud, Vasconcellos e Toledo Jr. (2011), o Plano Real conseguiu controlar a inflação via desindexação da economia, por meio da Unidade Real de Valor (URV) e de uma combinação de política monetária austera (a oferta de moeda passou a ser exógena) com a vigência da âncora cambial. Os efeitos dessa política econômica sobre as contas públicas foram: do lado do gasto, houve forte crescimento do serviço da dívida pública; e, do lado da receita, houve perda da receita de senhoriagem.

As esferas estaduais, por sua vez, não podiam mais contar com a redução dos gastos reais, via adiamento de compromissos, nem com as receitas financeiras provenientes de aplicação no mercado financeiro, e, enquanto o governo federal se financiava via emissão de títulos públicos, os estados se viram obrigados a renegociar suas dívidas por intermédio do Programa de Reestruturação Fiscal e Financeira (PRFF) (lei federal n. 9.496/97).

Até o final de 1998 e início de 1999, não havia, principalmente, por parte do governo federal, um compromisso claro por um ajuste fiscal capaz de conter o crescimento da dívida pública. Diante do desempenho fiscal ruim, sob pressão de mais uma crise externa, em 1999, o Brasil recorre ao Fundo Monetário Internacional (FMI) como tentativa de prolongar a vida do regime de câmbio administrado, metas duras de resultado primário foram estabelecidas, como uma porcentagem do Produto Interno Bruto (PIB), com o objetivo explícito de reverter os altos níveis de 
dívida pública acumulados no período anterior. Ao mesmo tempo, medidas estruturais foram aprovadas no Congresso Nacional, alterando as regras para aposentadoria no Regime Geral de Previdência Social (RGPS) e estabelecendo uma Lei de Responsabilidade Fiscal (LRF) que visava a introduzir uma restrição institucional efetiva às políticas fiscais, abrangendo todos os níveis de governo.

No caso do Rio Grande do Sul, a situação das finanças públicas agravou-se em função da deterioração da situação fiscal do estado, da baixa taxa média de crescimento do produto real no período e das elevadas taxas de juros reais praticadas pelo Banco Central (BC) (MARQUES JUNIOR, 2012). A situação fiscal deteriorou-se em razão de uma política fiscal expansionista praticada entre 1995 e 1998.

Com a desconfiança, por parte do mercado, da capacidade de pagamento e de rodagem da dívida, levaram o estado, em abril de 1998, a refinanciar parte da sua dívida de R\$ 7,7 bilhões, no âmbito do Programa de Reestruturação Fiscal e Financeira. O estado não entrou em insolvência, como destaca Marques Junior (2012), por conta de recursos extraordinários obtidos por meio das privatizações realizadas durante os anos de 1996 a 1998.

Neste retrato das contas públicas dos entes federados, a Lei de Responsabilidade Fiscal ao consolidar regras quantitativas e de procedimentos que visavam à redução do grau de discricionariedade nas políticas orçamentária e fiscal, definiu um arcabouço mais robusto e abrangente para a política fiscal a ser seguido por todos os níveis de governo. Assim, aumentou a transparência das contas públicas; procurou integrar os processos orçamentários e de planejamento, visando a melhorar a qualidade das políticas públicas; e fortaleceu o compromisso com níveis sustentáveis de endividamento. Para Giambiagi e Além (2008) representa um marco definitivo no processo de institucionalização de práticas fiscais sustentáveis.

Para alcançar esses objetivos, a lei estabeleceu tetos para a razão entre despesas com pessoal e receitas correntes líquidas (RCL) e determinou que os orçamentos anuais fossem elaborados e implementados, objetivando alcançar metas para os resultados nominal e primário definidos nas leis de diretrizes orçamentárias. A lei também determinou que fossem fixados limites para a dívida líquida dos estados relativamente às suas RCLs e que o Senado, que tem a responsabilidade sobre questões de dívida pública, fizesse o mesmo para o governo federal, medida essa ainda pendente de encaminhamento. Por fim, a LRF limitou o novo endividamento ao volume projetado de gastos de capital.

A trajetória da implementação concreta da LRF na administração pública municipal, estadual e federal vem sendo objeto de diversas análises. A questão que norteia este artigo indaga se a Lei de Responsabilidade Fiscal contribui para melhoria dos indicadores fiscais do estado do Rio Grande do Sul. Para responder a 
esse questionamento, tem-se como metodologia de pesquisa um estudo descritivo, quantitativo, com base em um estudo de caso. As informações foram obtidas junto ao banco de dados da Contadoria e Auditoria Geral do Estado (Cage-RS), no qual são descritos e analisados: o resultado primário e nominal; a evolução da dívida fiscal líquida, em comparação com o Produto Interno Bruto (PIB) e a Receita Corrente Líquida (RCL); o comportamento da receita e do gasto em proporção ao PIB; o comportamento do gasto com pessoal; a capacidade de investimento do estado; e, por fim, a estrutura do gasto por função de governo.

O estudo está estruturado em cinco capítulos. O primeiro, denominado de introdução, contextualiza o tema a ser pesquisado, bem como apresenta o objetivo da pesquisa. O segundo, traz uma abordagem histórica da implementação do Plano Real e da aprovação da Lei de Responsabilidade Fiscal. No terceiro, é realizado uma análise da Lei de Responsabilidade Fiscal, apresentando experiências internacionais que contribuíram para sua formatação e estruturação legal no Brasil. No quarto capítulo, analisa-se o desempenho fiscal do estado do Rio Grande do Sul no período de 2004 a 2012. No último capítulo, são tecidas as considerações finais.

\section{Plano Real: da estabilização da inflação aos problemas fiscais}

Desde 1986, a economia brasileira passou por diversos planos de estabilização, baseados em âncoras cambiais, congelamento de preços, ou ambos, com elevado conteúdo de intervenção governamental. Na seuqnecia pontua-se os nomes dos planos e suas respectivas datas: Plano Cruzado - fevereiro de 1986; Plano Bresser - junho de 1987; Plano Verão - janeiro de 1989; Plano Collor I - março de 1990; Plano Collor II - janeiro de 1991; Plano Real - junho de 1994.

Somente com o sexto plano, denominado de Plano Real, em 1994, que teve como característica uma etapa de transição que permitiu a acomodação dos preços relativos antes do plano e implementado em condições externas muito mais favoráveis, com abundância de capitais, elevadas reservas internacionais e maior abertura às importações, é que se chegou a um êxito duradouro.

O Plano Real, como destacam Gremaud, Vasconcellos e Toledo Jr. (2011), foi um dos planos mais engenhosos de combate à inflação do Brasil. Assim como o Plano Cruzado, partiu do diagnóstico de que a inflação brasileira tinha um forte caráter inercial. ${ }^{1}$ Ao contrário do Plano Cruzado, que optou por uma estratégia do choque heterodoxo (congelamento de preços), o Plano Real optou pela adoção da proposta de Reforma Monetária. $^{2}$ 
Desde sua concepção, em 1993, quando Fernando Henrique Cardoso (FHC) assumiu o Ministério da Fazenda, traçou-se um processo para o plano de estabilização sem incorrer nos erros dos planos anteriores. Em primeiro lugar, o plano não seria adotado de surpresa, mas sim gradualmente. Em segundo lugar, não iria recorrer a congelamentos, mas a uma "substituição gradual da moeda".

A concepção gradativa do plano real beneficiou-se do contexto, no qual o país havia reingressado no fluxo voluntário de recursos externos, tendo acumulado um volume significativo de reservas; a economia estava mais exposta à concorrência devido ao processo de abertura comercial, limitando a capacidade de os agentes repassarem para os preços os choques decorrentes desse contexto. Enfim, a inserção internacional do país era completamente distinta da vigente dos planos anteriores (GREMAUD; VASCONCELLOS; TOLEDO Jr., 2011).

Conforme destacam Belluzzo e Almeida (2002), o método adotado no Plano Real seguiu um modelo básico utilizado para dar fim à maioria das "grandes inflações" do Século XX: a recuperação da confiança da moeda nacional, por meio da garantia de seu valor externo.

O Plano dividiu o ataque ao processo inflacionário em três fases:

I- ajuste fiscal;

II- indexação completa da economia - Unidade Real de Valor (URV);

III- reforma monetária - transformação da URV em reais (R\$) (GREMAUD, 2011, p. 449).

O ajuste fiscal visava equacionar o desequilíbrio orçamentário para os próximos anos e impedir que daí decorressem pressões inflacionárias. Esse ajuste baseava-se em três elementos principais: corte de despesas - Plano de Ação Imediata (Pai); corte de despesas com pessoal e investimentos; aumento de impostos - criação do Imposto Provisório sobre Movimentação Financeira (IPMF); e diminuição das transferências do governo federal - Fundo Social de Emergência (FSE) alimentado por $15 \%$ das receitas de impostos em que a União não teria que cumprir as vinculações determinadas na Constituição de 1988 (GREMAUD; VASCONCELLOS; ROLEDO Jr., 2011).

Essas medidas, de caráter temporário, serviram para dar um fôlego fiscal, mas não se constituíram em solução definitiva. Nesse prazo, o governo deveria fazer o ajuste necessário como: transferência de obrigações aos municípios e estados (saúde, educação, habitação), e avançar na reforma tributária, administrativa e previdenciária. 
A segunda fase iniciou em fevereiro de 1994. Correspondia ao novo sistema de indexação, que objetivava simular os efeitos de uma hiperinflação - encurtamento de prazos de reajustes (indexação diária) "substituição parcial da moeda", sem passar por seus efeitos, e corrigir os desequilíbrios de preços relativos. Para tal, o governo criou um novo indexador, a Unidade Real de Valor (URV), cujo valor em cruzeiros reais seria corrigido diariamente pela taxa de inflação medida pelos principais índices (IGPM, IPC-FIPE, IPCA-Especial), que passaria a funcionar como unidade de conta no sistema. O valor da URV, nessa fase, manteria a paridade fixa de um para um dólar, ou seja, seu valor seria a própria taxa de câmbio.

Na terceira fase, quando todos os preços estavam expressos em URV, o governo introduziu o Real $(\mathrm{R} \$)$ como nova moeda, em $1^{\circ}$ de julho de 1994, cujo valor era igual ao da URV (e, por conseguinte, ao US\$) do dia CR $\$ 2.750,00$. Assim, todos os preços em CR\$ eram convertidos em $\mathrm{R} \$$, dividindo-se pelo valor da URV do “dia D”.

O impacto imediato do Plano Real foi a queda da taxa de inflação, a qual não ocorreu de forma abrupta e não caiu imediatamente para zero nem houve deflação. Tivemos uma taxa de inflação elevada em julho, mas já uma queda para $3 \%$ a.m. em agosto frente a $40 \%$ a.m. no primeiro trimestre.

Porém, o controle da inflação pós-Plano-Real, levou o país a conviver com elevados déficits fiscais. Como explica Matias-Pereira (2006), isso se deve à redução drástica da inflação, que funcionava como um imposto e facilitava ao governo cumprir o seu orçamento. Sem a inflação e sem dispor de uma base tributária consistente, a saída encontrada pelo governo federal para sustentar o plano real foi o endividamento público. Assim, a principal consequência do desequilíbrio fiscal foi o rápido aumento Dívida Líquida do Setor Público (DLSP).

O efeito da inflação nas contas fiscais, como esclarece Levy (2010), é conhecido como "efeito anti-Tanzi". Esse efeito decorre da assimetria que existiria entre as receitas ("perfeitamente" indexadas) e despesas fiscais (pouco indexadas), e que sob inflação elevada teria um impacto positivo sobre o resultado primário. Esse efeito seria causado pela capacidade que os gestores públicos teriam de controlar o valor real do gasto público, por meio dos atrasos de pagamentos, que resultavam em significativa redução do valor do dispêndio quando a inflação alcançava $1 \%$ ao dia, como era o caso no momento da implantação do Plano Real (MATIAS-PEREIRA, 2006).

Neste contexto, a dívida pública, no primeiro ano de mandato de $\mathrm{FHC}$, em janeiro de 1995, representava 30\% do PIB. No início do seu segundo mandato, em dezembro de 1999, a dívida líquida total do setor público havia atingido $53 \%$ do PIB (MATIAS-PEREIRA, 2006). 
No que se refere ao resultado primário, nos quatro anos seguintes ao plano, esse apresentou um déficit médio de 0,2\% do PIB (LEVY, 2010). A queda nos superávits primários revelou as fragilidades das posições fiscais que eram mascaradas pela inflação anterior. Combinadas com as altas taxas de juros requeridas para manter o controle sobre a taxa de câmbio, os superávits primários mais baixos geraram um aumento dos déficits nominais e a expansão da relação dívida/PIB.

Como destacam Belluzzo e Almeida (2002), a utilização da âncora cambial, como estratégia de contenção da inflação, deveria ser temporária e que, mantidas as condições básicas do financiamento externo às economias emergentes, a estabilização definitiva somente poderia ser alcançada mediante um ajustamento fiscal consistente no ponto de vista intertemporal.

Na verdade, como assinala Levy (2010), tanto os desequilíbrios gerados nos primeiros quatro anos de estabilização, entre 1995 e 1998, quanto as mudanças realizadas para eliminar aqueles desequilíbrios e consolidar um arcabouço consistente que estimulasse o crescimento giram em torno da capacidade de o país enfrentar seus problemas fiscais. A incapacidade de enfrentar os desequilíbrios fiscais simultaneamente ao controle da inflação teve influência sobre as escolhas das políticas após o Plano Real e levou a uma dependência exagerada em relação à administração da taxa de câmbio, entre 1995 e 1998, como mecanismo de manter a inflação baixa.

Nesse cenário, começa em 1999 uma mudança do regime fiscal. Sob pressão de mais uma crise externa, e tendo recorrido ao FMI numa tentativa de prolongar a vida do regime de câmbio administrado, metas duras de superávit primário para o setor público consolidado foram estabelecidas (como porcentagem do PIB) com o objetivo explícito de reverter os altos níveis de dívida pública acumulados no período anterior. Ao mesmo tempo, medidas estruturais foram aprovadas no Congresso alterando as regras de aposentadoria no Regime Geral de Previdência Social (RGPS) e estabelecendo uma Lei de Responsabilidade Fiscal(LRF) que visava introduzir uma restrição institucional efetiva às políticas fiscais, abrangendo todos os níveis de governo. A próxima seção aborda a implantação da LRF e os seus principais instrumentos de ajuste fiscal.

\section{Lei de Responsabilidade Fiscal}

Na literatura especializada, já é consolidado o conceito de que, na Lei de Responsabilidade Fiscal cuja gestão das finanças públicas é um dos fatores que pode colocar em risco a própria estabilidade do estado democrático. A esse se pode 
adicionar a crise econômica, política e social, os quais afetam a legitimidade e a credibilidade dos cidadãos nos agentes políticos e nos gestores públicos. Mesmo que existam instituições democráticas firmemente estabelecidas, os cidadãos sentem-se frequentemente impotentes para influenciar as políticas nacionais e controlar a aplicação dos recursos públicos.

A mensagem n. 485, encaminhada pela Presidência da República ao Congresso Nacional em 1999, encaminhou o Projeto de Lei que recebeu o n. 18/1999 e veio a transformar-se na Lei Complementar n. 101, promulgada em 4 de maio de 2000 e publicada no Diário Oficial da União (DOU) do dia 5 de maio do mesmo ano, a qual veio a ser denominada de Lei de Responsabilidade Fiscal. Esaa lei veio preencher um vácuo institucional e dar eficácia a vários dispositivos da Constituição Federal, especialmente aos seus arts. 163 e 169, que têm por objetivo estabelecer normas de finanças públicas voltadas para a responsabilidade da gestão fiscal.

Essa lei fundamenta-se em três princípios básicos: imposição de limites para os gastos públicos, atribuição de responsabilidades ao gestor e transparência na sua atuação e apoia-se em quatro pilares: o planejamento, a transparência, o controle e a responsabilização.

Três conceitos encontrados na LRF tem feito com que a essa lei esteja presente na linguagem cotidiana dos governantes e especialistas em finanças públicas. $\mathrm{O}$ principal é o resultado fiscal do governo, conhecido como Necessidades de Financiamento do Setor Público (NFSP), ${ }^{3}$ que avalia o desempenho fiscal da Administração Pública em determinado período de tempo. Este índice apura o montante de recursos que o setor público necessita captar junto ao setor financeiro interno e/ou externo, além de suas receitas fiscais, em face de seus dispêndios.

As NFSP são apuradas nas três esferas de governo, tais sejam, federal, estadual e municipal. Com a LRF, as leis de diretrizes orçamentárias de cada ente da federação deverão indicar os resultados fiscais pretendidos para o exercício financeiro ao que se referir a lei e os dois seguintes.

No âmbito federal, as NFSP são apuradas separadamente pelo orçamento fiscal e da seguridade social e pelo de investimento das estatais. $\mathrm{O}$ resultado do orçamento fiscal e da seguridade social recebe o nome de Necessidade de Financiamento do Governo Central, enquanto o resultado do orçamento de investimentos recebe o nome de Necessidade de Financiamento das Empresas Estatais.

Os outros dois conceitos que ganharam maior visibilidade a partir da LRF são os de Resultado Primário e Resultado Nominal, assim, definidos por Castro (2004, p. 164): 
Resultado Primário: mede o comportamento fiscal do governo no período, representando a diferença entre a arrecadação de impostos, taxas e contribuições e outras receitas inerentes à função arrecadadora do Estado, excluindo-se as receitas de aplicação financeiras. Este resultado é comparado com as despesas orçamentárias do governo no mesmo período, excluindo-se as despesas com amortização, juros e encargos da dívida, bem como as despesas com concessão de empréstimos. Em síntese avalia se o governo está gerando saldo em suas receitas permanentes para arcar com as despesas com juros, a fim de evitar aumentar sua dívida com o mercado.

Resultado Nominal: para apuração do resultado nominal, devem-se acrescentar ao resultado primário os valores pagos e recebido juros nominais. Desse modo, este resultado indica, efetivamente, o montante de recursos que o setor público financiou para a realização de suas despesas orçamentárias (quando negativo), ou quando economizou de suas receitas (quando positivo).

Existem duas formas de apuração do resultado nominal: "abaixo da linha" e "acima da linha". O resultado "abaixo da linha" considera apenas os itens de financiamento, apurando o desempenho fiscal do governo por intermédio do cálculo da variação do endividamento líquido em determinado período. Compara a dívida líquida (dívida menos disponibilidades e aplicações financeiras) do ano com a dívida líquida do ano anterior. Já o "acima da linha" apura o desempenho fiscal do governo mediante a apuração dos fluxos de receitas e despesas orçamentárias em determinado período.

Com a LRF buscou-se dar fim a um dos grandes problemas fiscais e macroeconômicos, que era o da fragilidade institucional. Sua existência já estava prevista na própria Constituição de 1988, que determinava a necessidade de uma lei complementar para a definição de padrões e implementação de mecanismos de controle para as finanças públicas. O seu principal objetivo foi estabelecer regras e fixar parâmetros para as finanças públicas consistentes com uma gestão fiscal responsável.

Isso envolveria o planejamento das ações fiscais e sua comunicação de forma transparente, dos orçamentos equilibrados, da antecipação de riscos, da correção de desvios e da introdução de mecanismos efetivos de enforcement (LEVY, 2010).

Porém, a experiência internacional, como destacado por Matias-Pereira (2006), demonstra que as regras fiscais - restrições à atuação governamental no campo das finanças públicas - por meio de lei não são suficientes para diminuir gastos públicos e evitar o déficit de um país ou de um estado. É preciso que, além dessas, os governantes tenham o compromisso político em conter os gastos. Destaca o autor que a análise dos desempenhos fiscais dos países que adotam essas regras fiscais, de maneira geral, mostra que as regras quantitativas (limites numéricos) tendem a ser mais eficazes que as de procedimento (conduta). E, que regras estabelecidas por lei não contribuíram para a melhoria do desempenho em boa parte dos países. 
A aplicação da Lei de Responsabilidade Fiscal, no Brasil, nos últimos anos, em que pese às resistências, dificuldades e distorções, evidencia que foi deflagrado o processo de combate crônico do desequilíbrio fiscal da Administração Pública brasileira, tanto em nível federal, estadual, como municipal. A partir dessas considerações, o estudo propõe-se a realizar uma avaliação dos resultados da LRF, no período de 2004 a 2012, no governo do estado do Rio Grande do Sul. Nessa análise, partiu-se do pressuposto que a LRF está firmando-se no ordenamento jurídico nacional.

\section{O desempenho fiscal do estado do Rio Grande do Sul no período de 2004 a 2012}

O descontrole da dívida no estado do Rio Grande do Sul acentua-se na década de 1970, com a "euforia" do período do milagre econômico, em que são realizados financiamentos internos e externos por meio da emissão de títulos da dívida pública (CAGE, 2012).

Na década de 1980 e, principalmente, 1990, a situação das finanças públicas agravou-se em função da deterioração da situação fiscal do governo estadual, de uma baixa taxa média de crescimento do produto real no período e das elevadas taxas de juros reais praticadas pelo Banco Central (MARQUES JUNIOR, 2012).

Com a desconfiança, por parte do mercado, da capacidade de pagamento e de rodagem da dívida, levaram o estado, em abril de 1998, a refinanciar parte da sua dívida, R \$ 7,7 bilhões, no âmbito do Programa de Reestruturação Fiscal e Financeira. O estado não entrou em insolvência, como destaca Marques Junior (2012), por conta de recursos extraordinários obtidos por meio das privatizações realizadas durante os anos de 1996 a 1998.

Ao assumir a maior parte dívida do estado pela União, esse assume o compromisso de pagar em trinta anos, com juros anuais de 6\% e correção pelo IGP-DI. As parcelas são limitadas em $13 \%$ da receita. Como o então governo, Antonio Britto, recebeu verbas do Programa de Incentivo à Redução do Setor Público Estadual na atividade bancária (Proes) para sanear o Banrisul, mas não privatizou o banco, uma parte do valor ficou fora do acordo, compondo a "dívida extralimite". Em função disso, o total pago acaba superando $13 \%$ da receita. A dívida refinanciada de $\mathrm{R} \$ 7,7$ bilhões, em 1998, apresentava saldo (principal mais resíduos), em 2010, de $\mathrm{R} \$ 36,2$ bilhões.

Assim, a LRF, ao estabelecer um conjunto de normas, limites e controles sobre as finanças públicas, voltadas a gestão fiscal responsável e uma busca do equilíbrio das contas públicas, foi concebida para ser um condutor na retomada da gestão 
fiscal dos entes federados. Na sequência, busca-se analisar o desempenho fiscal do estado do Rio Grande do Sul, pós Lei de Responsabilidade Fiscal - período de 2004 a 2012. Tendo por base informações do banco de dados da Contadoria e Auditoria Geral do Estado (Cage-RS), inicia-se, analisando o resultado primário e nominal; na sequência é apresentada a evolução da dívida fiscal líquida, em comparação com o PIB e com a Receita Corrente Líquida; posteriormente são analisados os comportamentos da receita e do gasto em proporção ao PIB; a análise do gasto com pessoal; a capacidade de investimento do estado; e, por fim, a estrutura do gasto por função de governo.

A evolução do resultado fiscal nas duas formas - primário e nominal - é apresentada no Gráfico 1. O resultado primário nas contas do governo do estado do Rio Grande do Sul, em 2004, primeiro ano do período em análise, apresentou resultado nulo (0,1\% do PIB), nos demais exercícios o resultado sempre se manteve próximo ou inferior a $1 \%$ do PIB. Esse baixo resultado primário contribuiu para o resultado de déficits nominais, que no período inicial de análise, representou $2 \%$ do PIB, apresentando decréscimo no período de 2005 a 2008, culminando com superávit nominal de $0,4 \%$ no exercício 2009, quando retoma o período de déficit em 2010, encerrando o período de análise em $1,6 \%$ do PIB.

Gráfico 1 - Resultados fiscais do estado do Rio Grande do Sul : período de 2004 a 2012 (\% PIB)



Fonte: elaborado pelo autor com base nos dados da Cage (2013).

De acordo com o TCERS, no período em análise, em oito exercícios financeiros o estado não atingiu as metas de resultado primário estabelecidas na Lei de Diretrizes Orçamentárias (LDO), metas essas apenas atingidas nos exercícios 2005 e 2008. Em relação às metas de resultado nominal, estabelecidas na LDO, o cenário 
é mais positivo, porém não tranquilizador, onde, nos exercícios de 2004 a 2007, e no exercício 2009, as metas foram atingidas, porém, no exercício 2008, e nos últimos três exercícios em análise, 2010 a 2012, os resultados ficaram abaixo do esperado.

A relação dívida/PIB manteve-se em decréscimo no período, a qual representava $22,2 \%$ em 2004, encerrando o período com uma participação de $17,5 \%$. Essa redução da participação dívida/PIB pode, em um primeiro momento, sinalizar como fator positivo da gestão fiscal, indicando uma redução no endividamento estadual, fato que não ocorreu. Assim, como salienta Belluzzo e Almeida (2002), uma melhor análise é compararmos a relação dívida/RCL.

Como demonstra o Gráfico 2, a relação dívida/RCL era de 207,1\% em 2004, apresenta pequena redução em 2005, e, retoma o crescimento em 2006, quando atinge expressiva participação de $253,6 \%$, nos anos posteriores retoma o período de queda, estabilizando essa relação em $218,1 \%$ no exercício 2012.

Em relação ao limite de endividamento, previsto na Lei de Responsabilidade Fiscal, e estabelecido no art. $3^{\circ}$, inciso I, da resolução SF n. 40/2001, que é de $200 \%$ da RCL, o Gráfico 2 mostra que em nenhum exercício analisado o estado conseguiu atingir esse limitador.

Gráfico 2 - Dívida pública (\% PIB e \% RCL): período de 2004 a 2012

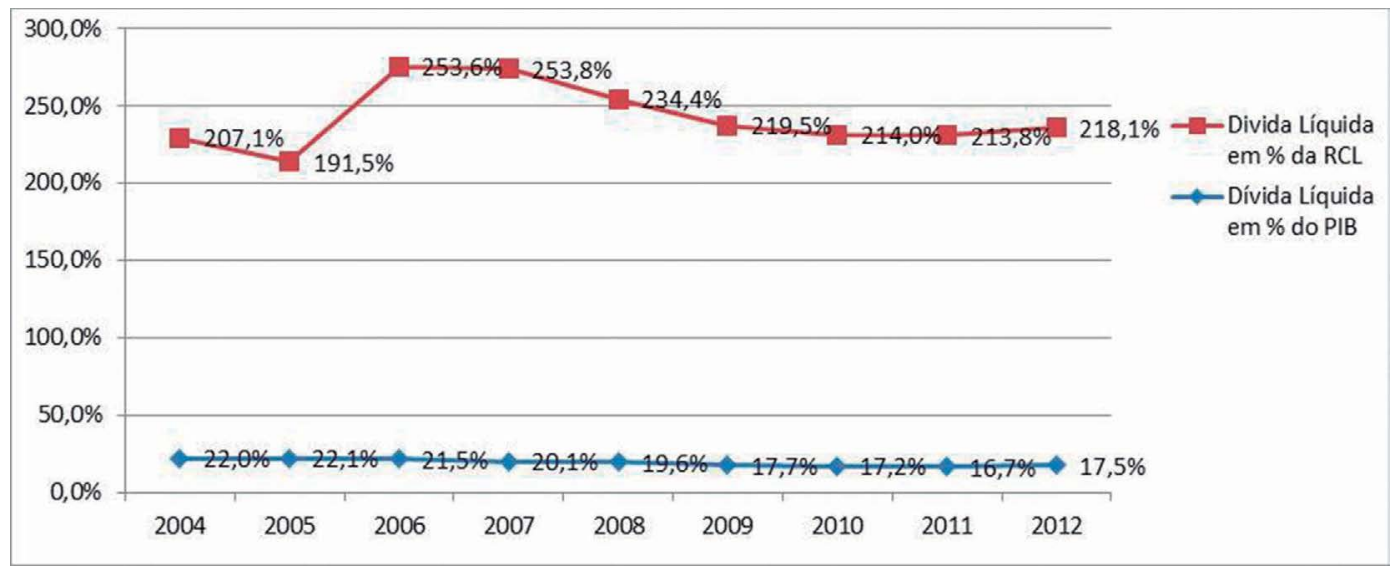

Fonte: elaborado pelo autor com base nos dados da Cage (2013).

A manutenção/elevação da proporção dívida pública em relação à RCL, não pode ser creditada ao fraco desempenho das receitas do estado. Como mostra o Gráfico 3, a participação da RCL sobre o PIB, que, em 2004, era de 7,5\%, passou para $8,6 \%$ no exercício seguinte, e manteve-se sempre acima dos $8 \%$ nos demais exercícios. 
Gráfico 3 - Proporção da RCL sobre o PIB: período de 2004 a 2012

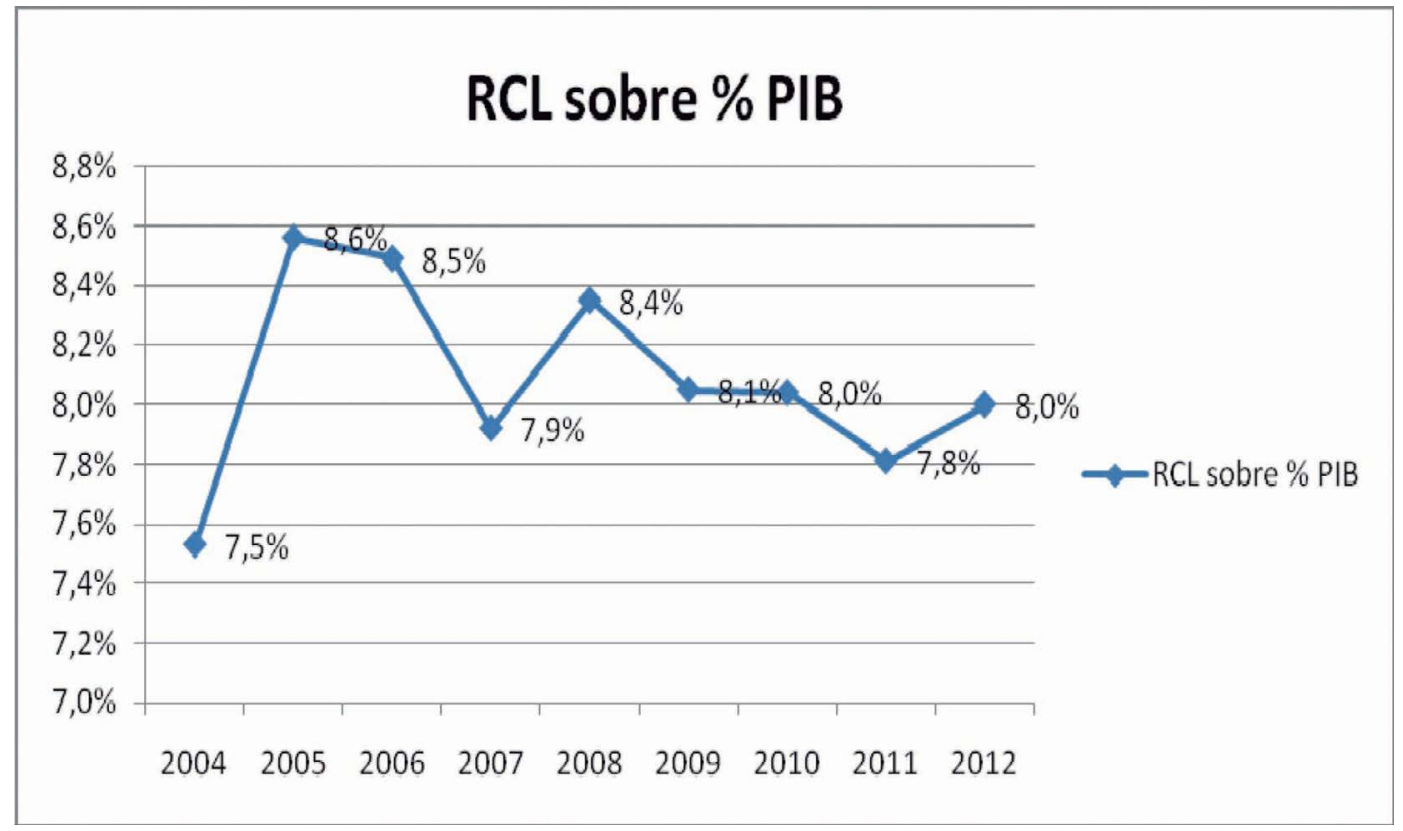

Fonte: elaborado pelo autor com base nos dados da Cage(2013).

No caminho contrário, o fraco desempenho fiscal pode ser creditado ao aumento da despesa conforme é mostrado no Gráfico 4. A despesa representava 10,8\% do PIB, com crescimento constante nos demais exercícios, atingindo $13,1 \%$ do PIB em 2012 , um crescimento de $21 \%$ no período, frente aos $8 \%$ de crescimento da receita no mesmo período. 
Gráfico 4 - Proporção gasto total do estado sobre PIB: período de 2004 a 2012.

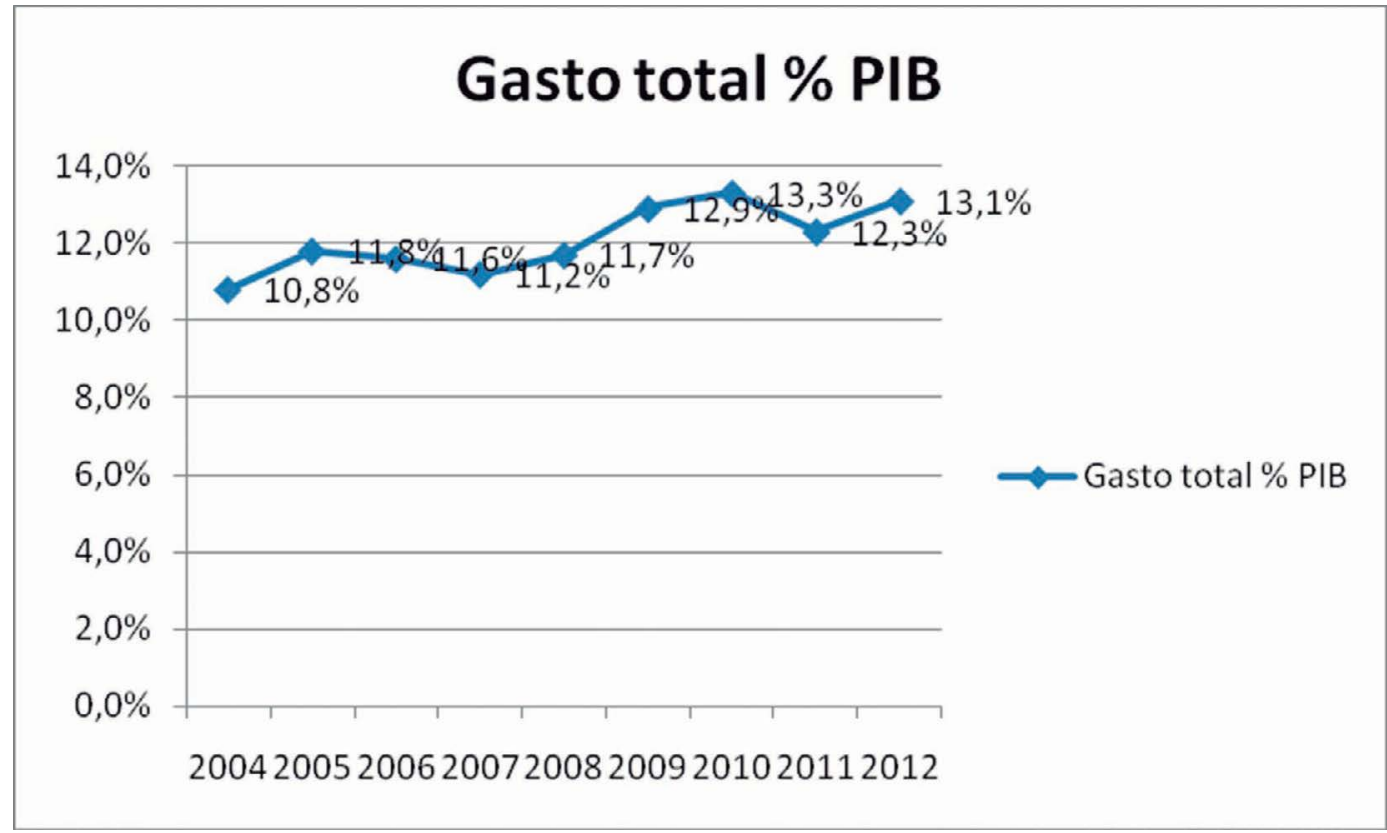

Fonte: elaborado pelo autor com base nos dados da Cage (2013).

Os principais componentes que contribuiem para a elevação da despesa do estado são os gastos com custeio, pessoal, custo da rodagem e o pagamento da dívida.

De acordo com Marques Junior (2012), as despesas de custeio estão associadas aos fatores de rigidez estrutural da despesa: vinculação da receita às despesas como educação e saúde; gastos sem controle dos Poderes (Judiciário, Legislativo, Ministério Público e Tribunal de Contas); e as demandas judiciais que obrigam o estado a despender considerável volume de recursos.

O gasto com pessoal, apesar de atender ao limite estabelecido na LRF (Gráfico 5), manteve-se próximo ou superior aos 50\% da RCL, percentual que pode ser considerado elevado. Fatores que contribuem para o elevado custo com pessoal são o crescimento vegetativo da folha de pagamento dos servidores ativos por conta de promoções automáticas por tempo de serviço e de outros direitos previstos nos planos de carreiras; crescimento vegetativo dos gastos com inativos e pensionistas em razão de pedidos de aposentadoria e demais direitos (MARQUES JUNIOR, 2010). 
Gráfico 5 - Comportamento das despesas com pessoal sobre a RCL: período de 2004 a 2012

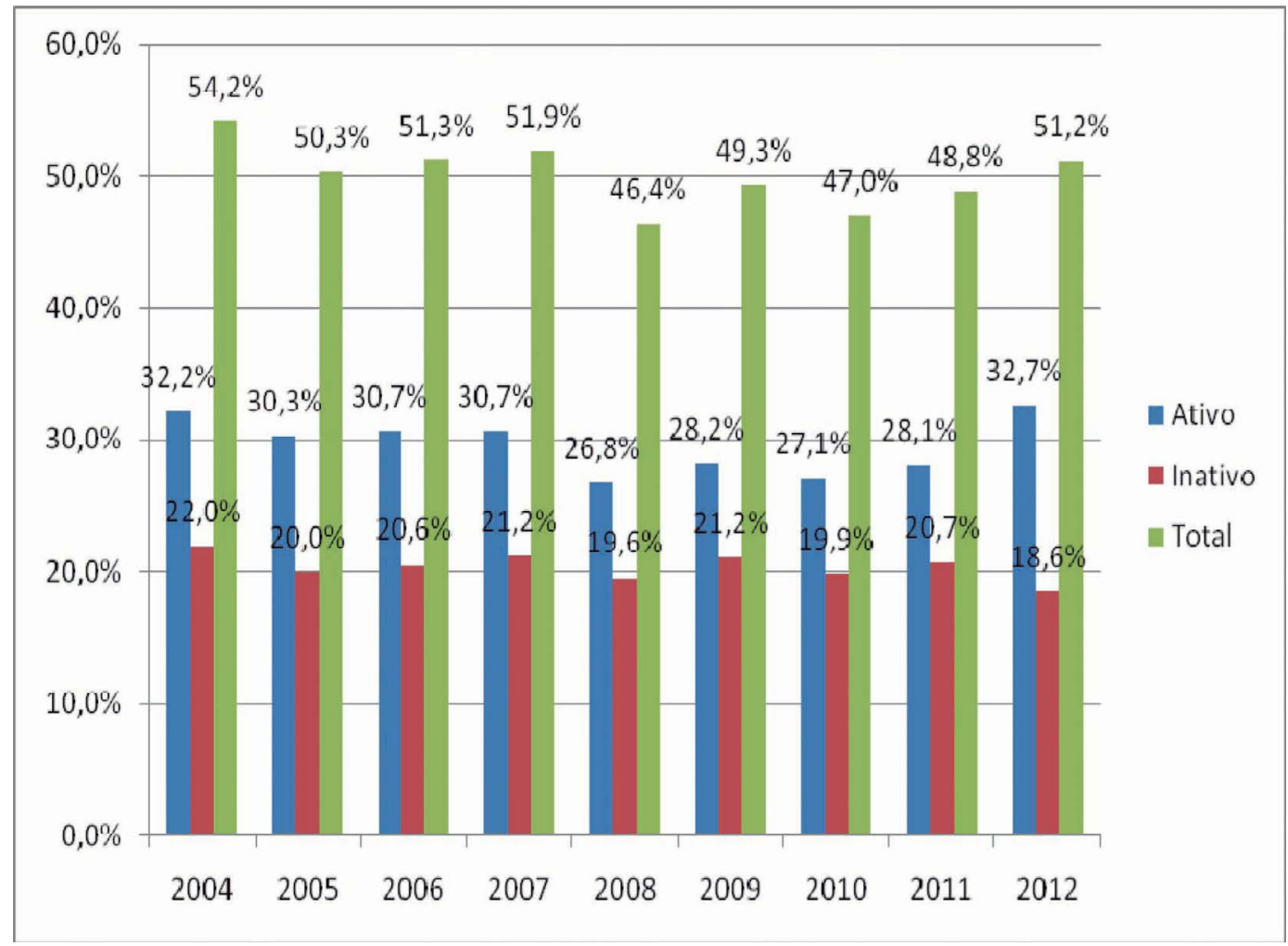

Fonte : elaborada pelo autor com base em dados da Cage (2013).

Para manter os compromissos em dia, as despesas de investimento são comprimidas, o que compromete o potencial de crescimento da economia gaúcha. Em 2004, os investimentos representavam 4,2\% do PIB, descrendo nos exercícios 2005 a 2008, quando atinge seu menor percentual de 2,1\%. Em 2009, e principalmente em 2010, ocorre um elevado crescimento nos investimentos, frutos de contratação de operações de crédito externas contratuais, que em 2010 representaram $R \$$ 786.825.000,00. Já nos exercícios de 2011 e de 2012 a capacidade de investimento volta a reduzir, atingindo $2,7 \%$ em 2012. 
Gráfico 6 - Investimento do estado em proporção ao PIB: período de 2004 a 2012

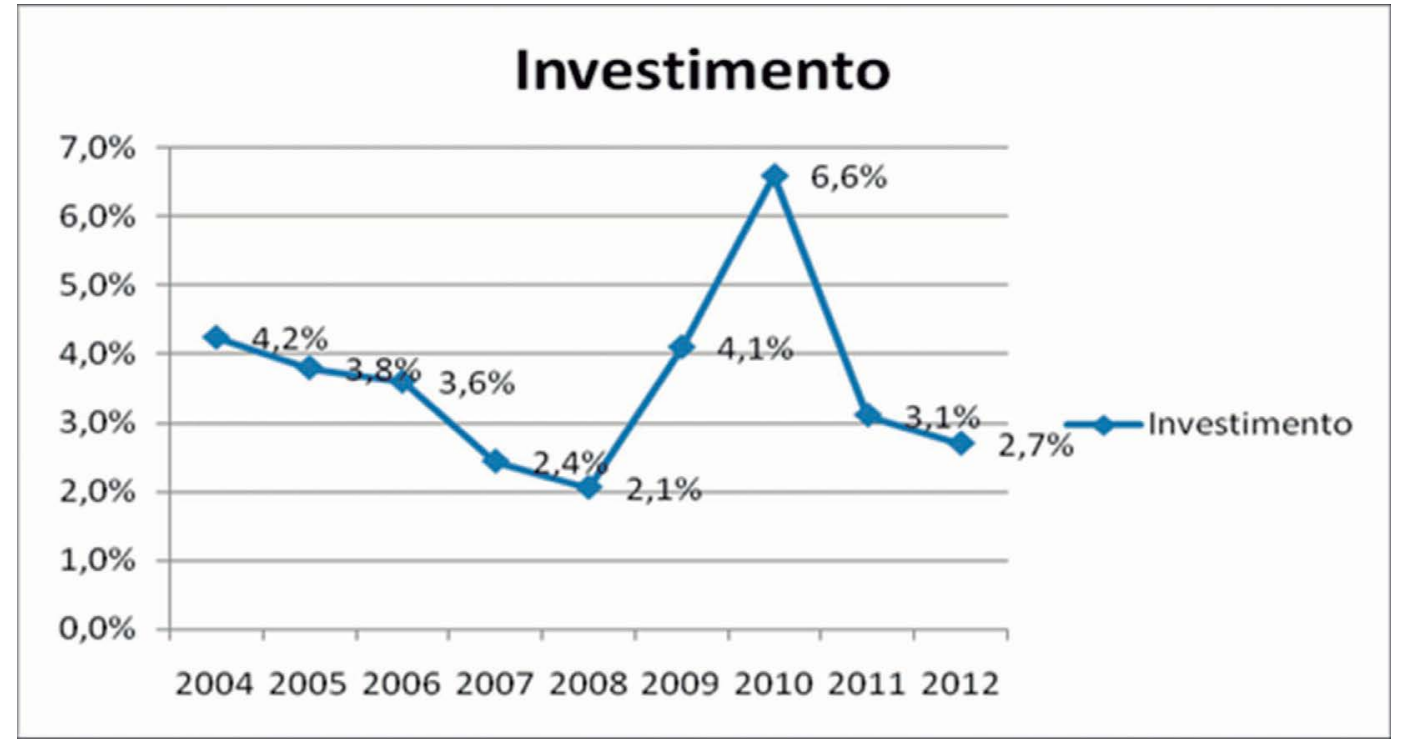

Fonte: elaborado pelo autor com base nos dados da Cage (2013).

A análise do gasto público pode ser ampliada para a qualidade de tal gasto. Uma forma de avaliar esta qualidade é o gasto por função. A classificação funcional da despesa, adotada no Brasil pela portaria n. 42 de 1999, do então Ministério do Orçamento e Gestão, segrega as dotações orçamentárias em funções e subfunções, buscando responder basicamente à indagação "em que" área de ação governamental a despesa será realizada. Essa é composta de um rol de funções e subfunções prefixadas, que servem como agregador dos gastos públicos por área de ação governamental nas três esferas de governo. Trata-se de classificação de aplicação comum e obrigatória, no âmbito da União, dos estados, do Distrito Federal e dos municípios, o que permite a consolidação nacional dos gastos do setor público.

Na Tabela 1 é apresentado as despesas por função de governo no estado do Rio Grande do Sul no período de 2004 a 2012. 
Tabela 1 - Despesas por função de governo: período de 2004 a 2012

\begin{tabular}{l|r|r|r|r|r|r|r|r|r}
\hline Função de governo & 2004 & 2005 & 2006 & 2007 & 2008 & 2009 & 2010 & 2011 & 2012 \\
\hline Previdência social & 17,0 & 29,0 & 29,0 & 320, & 21,0 & 31,0 & 29,0 & 32,0 & 32,0 \\
Encargos especiais & 20,0 & 16,0 & 16,0 & 14,0 & 21,0 & 15,0 & 17,0 & 13,0 & 14,0 \\
Sáude & 10,0 & 10,0 & 9,0 & 10,0 & 10,0 & 11,0 & 11,0 & 12,0 & 12,0 \\
Educação & 19,0 & 13,0 & 13,0 & 13,0 & 20,0 & 12,0 & 10,0 & 11,0 & 11,0 \\
Segurança pública & 8,0 & 9,0 & 10,0 & 10,0 & 8,0 & 9,0 & 8,0 & 8,0 & 9,0 \\
Administração & 5,0 & 4,0 & 4,0 & 4,0 & 5,0 & 5,0 & 6,0 & 6,0 & 6,0 \\
Transporte & 4,0 & 3,0 & 3,0 & 3,0 & 3,0 & 3,0 & 5,0 & 3,0 & 2,0 \\
Judiciário & 8,0 & 7,0 & 7,0 & 7,0 & 6,0 & 7,0 & 6,0 & 6,0 & 6,0 \\
Essência à Justiça & 3,1 & 3,1 & 3,2 & 2,9 & 2,7 & 2,9 & 2,9 & 2,8 & 2,8 \\
Legislativa & 2,7 & 2,4 & 2,3 & 2,1 & 2,0 & 2,5 & 2,3 & 2,4 & 2,4 \\
Agricultura & 1,8 & 1,5 & 1,6 & 1,3 & 1,2 & 1,3 & 1,3 & 1,4 & 1,6 \\
Trabalho & 0,3 & 0,3 & 0,3 & 0,3 & 0,2 & 0,2 & 0,2 & 0,2 & 0,2 \\
Indústria & 0,1 & - & - & - & - & - & - & 0,1 & 0,1 \\
Ciência e tecnologia & 0,3 & 0,2 & 0,2 & 0,2 & 0,2 & 0,3 & 0,3 & 0,3 & 0,2 \\
Cultura & 0,2 & 0,2 & 0,2 & 0,2 & 0,2 & 0,2 & 0,2 & 0,2 & 0,2 \\
Gestão ambiental & 0,3 & 0,3 & 0,2 & 0,2 & 0,2 & 0,2 & 0,3 & 0,3 & 0,3 \\
Assistência social & 0,8 & 0,7 & 0,7 & 0,7 & 0,6 & 0,7 & 0,6 & 0,7 & 0,5 \\
\hline
\end{tabular}

Fonte: elaborada pelo autor com base no banco de dados da Cage (2013).

Percebe-se que os gastos com a previdência social, que representavam $17 \%$ dos gastos totais em 2004, passaram para 32,0\% em 2012. Por sua vez, os gastos com encargos sociais (amortização da dívida, juros e tributos), que representavam $20 \%$ em 2004, findaram o decênio num percentual de $14 \%$.

Os gastos com áreas sociais como saúde e educação apresentaram comportamento distintos. O primeiro apresentou um leve crescimento, o qual representava $10 \%$ em 2004, passando para $12 \%$ em 2010. Já os gastos com o segundo apresentaram uma queda significativa, passando de 19\% em 2004 para $11 \%$ em 2012.

Os gastos com o setor administrativo e da atividade legislativa mantiveram-se estáveis no período, com uma média de média $8 \%$ do total da despesa do estado. Porém, esses gastos são maiores que a soma dos gastos em atividades fins do estado como: transporte, indústria, comércio e agricultura. Destaque para os gastos em transporte que sofreram uma queda de $50 \%$ no período.

Merece destaque, também, os gastos com o judiciário e essência à justiça, os mesmos, apesar de significativa redução no período, eram 11,1\% em 2004 passando para $8,8 \%$ em 2012, consomem parcela significativa do orçamento. Quando somados os gastos com segurança pública esses gastos se aproximam a $20 \%$ do total do gasto orçamentário. 
Diante da realidade apresentada, com fraco desempenho fiscal, motivado principalmente pelo elevado gasto público, este composto principalmente pelas despesas com: inativos, pessoal e encargos da dívida, tem reduzido e limitado a capacidade do estado em fazer investimento, bem como de apoiar áreas importantes para o desenvolvimento econômico, como: transporte, agricultura, trabalho, indústria e comércio. Também, a deterioração fiscal do estado, tem impedido o apoio deste em áreas que demandam por recursos na atualidade, como: gestão ambiental, ciência e tecnologia, cultura, que juntas não somam $1 \%$ do total dos gastos do estado.

\section{Considerações finais}

A gestão das finanças públicas no Brasil passaram a ter um novo regramento com a promulgação da Lei de Responsabilidade Fiscal, em 4 de maio de 2000. Esta legislação estabeleceu regras relacionadas ao endividamento público, limitou gastos (principalmente com pessoal) e fortaleceu a necessidade da arrecadação das receitas públicas. Também consolidou conceitos como a Necessidade de Financiamento do Setor Público (NFSP), Resultado Nominal e Resultado Primário, que objetivam melhorar a condução e o desempenho da gestão fiscal, nas três esferas federadas.

No estado do Rio Grande do Sul, a obtenção de resultados primários positivos, em todos os exercícios no período de 2004 a 2012, não foi suficiente para a melhoria do resultado nominal das contas públicas, o que vem mantendo a dívida pública do estado no maior patamar, seja em comparação ao PIB (18\%) ou da RCL (218\%), às demais Unidades da Federação (UF).

O elevado custo da dívida pública do estado do RS, aliado ao elevado gasto com pessoal (52\% da RCL em 2012) gerado principalmente pelo aumento dos gastos com previdência social, saltou da casa dos $17 \%$ em 2004, para $32 \%$ em 2012 , tem retirado a capacidade de investimento que tem se mantido na média de $2,5 \%$ do PIB no período.

Os números demonstram que apesar da importância de normas como a LRF, essas não são suficientes para, por si só, garantir a melhoria da situação fiscal do estado do RS. É preciso esforço político para enfrentar os desafios estruturais necessários, como reforma do sistema de previdência e, austeridade no gasto público que, em apenas uma década, cresceu $3 \%$, atingindo $13 \%$ do PIB, tendo a receita permanecido no patamar de $8 \%$.

Essas reformas são fundamentais para elevar a capacidade de investimentos e possibilitar que áreas, que tem recebido reduzidos incentivos do estado, como ciência e tecnologia, indústria, agricultura, passem a ser priorizadas, conduzindo o estado para novos rumos em um médio espaço de tempo. 


\title{
Performance audit of Rio Grande do Sul: an analysis of post Fiscal Responsibility Act - 2004-2012
}

\begin{abstract}
The weight of public debt to public finances in the state of Rio Grande do Sul has centered discussions: political, budgetary, financial, over the past three decades, where he is assigned the blame for the low levels of investment and constant primary deficits. In this scenario, the Fiscal Responsibility Law (Complementary Law No. 101/2000), to consolidate quantitative and procedures aimed at reducing the degree of discretion on the budget and tax policies, rules defined a more robust and comprehensive framework for fiscal policy to be followed by all levels of government. Thus, we aimed at evaluating whether the LRF contributes to improving fiscal indicators of the state of Rio Grande do Sul, with the period of analysis the years 2004-2012. Through a descriptive, quantitative, based on a case study, it was found that, despite the importance of standards such as LRF, this was not enough, by itself, ensure improved fiscal situation of RS, where public spending and borrowing were superior to the Current Net Revenue growth.
\end{abstract}

Keywords: Government debt. Fiscal responsibility law. Public finance. State of Rio Grande do Sul

\section{Rendimiento de auditoría de Rio Grande do Sul: un análisis de la Ley de Responsabilidad Fiscal de post - 2004-2012}

\section{Abstracto}

El peso de la deuda pública de las finanzas públicas en el estado de Rio Grande do Sul ha centrado las discusiones: políticos, presupuestarios, financieros, en las últimas tres décadas, en el que se asigna la culpa de los bajos niveles de inversión y constantes déficits primarios. En este escenario, la Ley de Responsabilidad Fiscal (Ley Complementaria № 101/2000), para consolidar cuantitativa y procedimientos destinados a reducir el grado de discrecionalidad sobre el presupuesto y las políticas fiscales, reglas define un marco más sólido y amplio para la política fiscal para ser seguido por todos los niveles de gobierno. Por lo tanto, el objetivo fue evaluar si la LRF contribuye a la mejora de los indicadores fiscales del estado de Rio Grande do Sul, con el período de análisis de los años 2004 a 2012. A través de un estudio descriptivo, cuantitativo, basado en un estudio de caso, se encontró que, a pesar de la importancia de las normas, como LRF, esto no fue suficiente, por sí sola, garantizar la mejora de la situación fiscal de RS, donde el gasto público y el endeudamiento eran superiores al crecimiento actual neto de Rentas.

Palabras clave: La deuda pública. Ley de responsabilidad fiscal. Finanzas Públicas. Estado de Río Grande do Sul. 


\section{Notas}

1 O diagnóstico inercial considera dois componentes: o choque e a tendência, em que o último é a que faz com que a inflação perpetue-se em determinado patamar, esse, também, é o principal componente para que o combate a inflação tenha sucesso, em que se deve garantir que após o rompimento da tendência, não se verifiquem choques na economia, ou que existam mecanismos para que o choque possa ser dissipado.

2 Antes do Plano Cruzado, a proposta para o combate a inflação se concentrou em dois grupos: "o choque heterodoxo" (Francisco Lopes), que se baseava no congelamento de preços, e a "Reforma Monetária" (Larida), que correspondia à simulação dos efeitos de uma hiperinflação como o convívio de duas moedas, uma boa e uma ruim, com a primeira substituindo a outra ao longo do tempo.

3 Necessidade de Financiamento do Setor Público conceito nominal (NFSPcn): engloba qualquer demanda de recursos pelo setor público, inclusive para fazer frente a despesas financeiras - pagamento do juro sobre a dívida pública. Necessidade de Financiamento do Setor Público conceito operacional (NFSPco): deduz as correções monetária e cambiam pagas sobre a dívida. Esse conceito é conhecido como déficit operacional do setor público.

\section{Referências}

BELLUZZO, L. G.; ALMEIDA, J. G. Depois da queda: a economia brasileira da crise da dívida aos impasses do Real. Rio de Janeiro: Civilização Brasileira, 2002.

BRASIL. Lei Complementar n. 101, de 4 de maio de 2000. Estabelece normas de finanças públicas voltadas para a responsabilidade na gestão fiscal e dá outras providências. Disponível em: <http:/www.planalto.gov.br/ccivil_03/leis/lcp/lcp101.htm>. Acesso em: 4 set. 2013.

CASTRO, Domingos Poubel. Contabilidade pública no governo federal: guia para reformulação do ensino e implantação da lógica do SIAFI nos governos municipais e estaduais com utilização do Excel. São Paulo: Atlas, 2004.

CONTADORIA E AUDITORIA GERAL DO ESTADO DO RIO GRANDE DO SUL - GAGE. Portal Transparência RS. Disponível em: <http://www.transparencia.rs.gov.br/webpart/system/AnaliseGrafica.aspx?Report=GrafCgpGrupo>. Acesso em: 12-13 set. 2013.

GIAMBIAGI, Fábio; ALÉM, Ana Cláudia Duarte de. Finanças públicas. 4. ed. Rio de Janeiro: Elsevier, 2008.

GONÇALVES, Marcos Flavio R. Traçando um panorama geral da Lei de Responsabilidade Fiscal/Marcos Flavio Gonçalves, Marlene Fernandes. Coordenação de Heraldo da Costa Reis, Tereza Cristina Baratta, GleisiHeisler Neves. Rio de Janeiro: IBAM/BNDS, 2001.

GREMAUD, Amaury Patrick; VASCONCELLOS, Marco Antonio Sandoval de; TONETO JÚNIOR, Rudinei. Economia brasileira contemporânea. 7. ed. São Paulo: Atlas, 2011.

LEVY, Paulo Mansur. A política fiscal no período Pós-Real: desempenho e instituições. In: SOUSA, M. C. Sampaio de; COELHO, I.; VERSIANI, F. R.; TANNURI-PIANTO, M. E. (Orgs.). Economia pública brasileira. Brasília: ESAF, 2010.

MATIAS-PEREIRA, José. Finanças públicas: a política orçamentária no Brasil. São Paulo: Atlas, 2006.

MARQUES JUNIOR, Liderau dos Santos. A dívida pública do RS e a proposta de se recriar divida estadual junto aos bancos privados. Textos para Discussão FEE, n. 099 (2012). Disponível em: <http://www.fee.tche.br/sitefee/pt/content/publicacoes/pg_tds_detalhe.php?ref $=099>$. Acesso em: 2 set. 2013 . 
OLIVEIRA, Regis Fernandes de. Responsabilidade fiscal. 2. ed. São Paulo: Editora dos Tribunais, 2002.

TRIBUNAL DE CONTAS do Estado do Rio Grande do Sul. Gestão fiscal. Disponível em: http://www1.tce.rs.gov.br/aplicprod/f?p=20001:7:0:::RP,7:P7_ESFERAS:E. Acesso em: 9 set. 2013. 